\title{
Screening of Fe-Deficiency Tolerance in Okra (Abelmoschus esculentus L.) Through Hydroponic Culture
}

\author{
Motiar RAHMAN, Mohammad S. ISLAM, Ahmad H. KABIR*, Syed A. HAIDER, \\ Nishit K. PAUL
}

University of Rajshahi, Department of Botany, Plant and Crop Physiology Laboratory, Rajshabi 6205, Bangladesh;

abmad.kabir@ru.ac.bd (*correspondingauthor)

\begin{abstract}
Screening for Fe deficiency tolerance in okra (Abelmoschus esculentus) Bangladeshi genotypes ('BARI-1', 'Local variety', 'Orca Onamica', and 'Prince') were studied based on different morphological and physiological parameters. Number of leaves, shoot height and weight were significantly reduced in 'Orca Onamica' and 'Prince', whereas 'BARI-1' and 'Local variety' did not show prominent decrease in the aforesaid growth parameters under Fe deficiency. Again, 'Orca Onamica' and 'Prince' showed significantly decreased root length and root biomass under Fe deficiency. In contrast, these parameters were unchangeable in 'BARI'-1 and 'Local variety' in Fe shortage compared to controls. Furthermore, Fe deficiency caused severe decrease in chlorophyll $(a$ and $b)$ and Fe concentrations in leaves of 'Orca Onamica' and 'Prince' grown on hydroponic culture. In contrast, chlorophyll $(a$ and $b$ ) and Fe concentrations were not significantly decreased in 'BARI-1' and 'Local variety' due to Fe deficiency. Based on these findings, tolerance to Fe deficiency in these okra cultivars can be categorized as: tolerant ('BARI-1' and 'Local'), and sensitive ('Orca Onamica' and 'Prince'). The ranking can be applied in plant breeding program and may have great advantage over conventional methods. This study also demonstrates the effectiveness of hydroponic culture as an efficient method to screen Feefficient crop plants.
\end{abstract}

Keywords: Abiotic stress, Fe concentration, Fe deficiency tolerance, hydroponic culture, okra, screening

\section{Introduction}

Iron $(\mathrm{Fe})$ is the fourth most abundant element in the earth's crust and is an essential nutrient for plants (Marschner, 1995). Fe deficiency-induced chlorosis is a common disorder in dicotyledonous plants, including field peas, when grown on calcareous, high $\mathrm{pH}$ soil (Marschner, 1995). Chlorosis may lead to serious yield, quality losses and economic loss (Molassiotis et al., 2005). Alkaline soils are regarded as potential inducers of Fe deficiency in plants even though the element might occur in high concentrations in the soil (Tangolar et al., 2008). Fe is absorbed by soil particles in an insoluble form, which the plants are not capable of utilising, and the soluble portion is usually insufficient (Lindsay, 1984). A high concentration of bicarbonate contributes to the soil alkalinity (Mengel et al., 1995). Fe in interaction with other nutrients may become scarcely available to the plants. Based on the World Reference Base Soil Classification System, calcareous soil is classified under the reference soil group of Calcisols covering 800 million hectares worldwide, mainly found in South Asia, Australia, West Asia and North Africa under arid and semi-arid climates or Mediterranean climates (Srinivasarao et al., 2006).

Okra (Abelmoschus esculentus) also known as lady's finger, is a valuable vegetable plant. Okra contains proteins, carbohydrates and vitamin C (Dilruba et al., 2009), and plays a vital role in human diet (Saifullah and Rabbani, 2009). Consumption of young immature okra pods is important as fresh fruits, and it can be consumed in different forms (Ndunguru and Rajabu, 2004). However, Fe deficiency causes poor yield in many okra genotypes grown worldwide. In agriculture, Fe deficiency tolerant cultivars offer advantages in Fe deficient soil as plants require minimal fertilizer applications. Thus, the trait of $\mathrm{Fe}$ deficiency tolerance has long been a subject of interest in agricultural science. Hydroponic culture has often been used for screening for tolerance to mineral deficiency and toxicity. Screening in hydroponic culture allows for rapid screening, it overcomes seasonal effects and provides disease free conditions (Dragonuk et al., 1989). Generally, Fe deficiency in hydroponic culture is induced by the addition bicarbonate which increases the $\mathrm{pH}$ of the solution making the solution Fe unavailable for plants (Zribi and Gharsalli, 2002). It has 
364

been the most popular method used to identify tolerant genotypes in crop plants such as soybean (Dragonuk et al., 1989), maize (Celik and Katkat, 2008), chickpea (Hamze $e t$ al., 1987) and wheat (Chaney, 1984). Although hydroponic screening is suitable for preliminary work, field evaluation is required to confirm the results do apply in soil (Dragonuk $e t$ al., 1989). However, screening of Fe deficiency tolerance in okra was not yet performed.

Different morphological parameters are used to screen for genotypes tolerant to Fe deficiency in plants (Dwyer $e t$ al., 1991; Yakop, 2008). The most widely used parameter for screening Fe deficiency tolerant genotype in plants is chlorophyll score. Chlorophyll has been used for screening several species including corn (Dwyer et al., 1991), wheat (Reeves et al., 1993), sweet pepper (Madeira et al., 2003) and field peas (Yakop, 2008). Use of SPAD-502 is reported to be more accurate than visual assessment of chlorophyll (Reeves et al., 1993) and appropriate to assess Fe deficiency chlorosis in leaves (Yakop, 2008). Other morphological features, such as, root/shoot ratio, leaf and root growth have also been used to screen Fe deficiency tolerant plant species (Bertoni et al., 1992; Kosegarten, 1999; Yakop, 2008). To date, no investigation was done on the screening of $\mathrm{Fe}$ efficiency okra line based on morphological and physiological parameters.

Growing Fe deficiency tolerant cultivars in Fe deficient soils could be economically preferable as it does not need application of any Fe compounds. However, selection of nutrient tolerant genotype is dependent on the suitable screening method. Therefore, genotypic differences in Fedeficient plants based on physiological and biochemical responses have long been the subjects of intensive studies. A large number of new field okra varieties with improved characteristics have been released in recent years. Nevertheless, very little is known towards the screening of okra genotypes tolerant to Fe deficiency. Thus, the present investigation was aimed at screening different okra genotypes mainly cultivated in Bangladesh. Further aim of this study was to establish the hydroponic method for screening Fe deficiency genotypes.

\section{Materials and methods}

\section{Plant materials}

Four okra genotypes ('BARI-1', 'Local variety', 'Orca Onamica' and 'Prince') were collected from local seed market.

\section{Germination and growth conditions}

Before growing, seeds were surface sterilized in $70 \%$ ethanol and 5\% sodium hypochlorite for 1 and $15 \mathrm{~min}$, respectively. Seeds were then rinsed five times in deionised water. Seeds were germinated on moist filter paper wetted with deionised water for 3-4 days in the dark at room temperature. Only healthy and uniform seedlings were transplanted to solution culture. A basal nutrient solution (Hoagland and Arnon, 1950) was used with the following nutrient concentrations $(\mu \mathrm{M}): \mathrm{KNO}_{3} \quad(16000)$, $\mathrm{Ca}\left(\mathrm{NO}_{3}\right)_{2} .4 \mathrm{H}_{2} \mathrm{O}$ (6000), $\mathrm{NH}_{4} \mathrm{H}_{2} \mathrm{PO}_{4} \quad$ (4000), $\mathrm{MgSO}_{4} .7 \mathrm{H}_{2} \mathrm{O}$ (2000), $\mathrm{KCl}(50), \mathrm{H}_{3} \mathrm{BO}_{3}(25)$, Fe-EDTA (25), $\mathrm{MnSO}_{4} .4 \mathrm{H}_{2} \mathrm{O}$ (2), $\mathrm{ZnSO}_{4}(2), \mathrm{Na}_{2} \mathrm{MoO}_{4} .2 \mathrm{H}_{2} \mathrm{O}(0.5)$ and $\mathrm{CuSO}_{4} .5 \mathrm{H}_{2} \mathrm{O}(0.5)$. Target $\mathrm{pH}$ values were obtained by titrating the basal solution with $\mathrm{KOH}$ or $\mathrm{H}_{2} \mathrm{SO}_{4}$. Plants were grown in $2 \mathrm{~L}$ of aerated solution and the environment was strictly maintained under $10 \mathrm{~h}$ light and $14 \mathrm{~h}$ dark (550$560 \mu \mathrm{mol} s-1$ per $\mu \mathrm{A})$. Fe deficiency was induced by adding $\mathrm{NaHCO}_{3}(10 \mathrm{mM})$ to the treatment solutions to increase the $\mathrm{pH}$ up to 8.0 to initiate Fe deficiency as previously described (Kabir et al., 2013; Gharsalli et al., 2001). Solution was replaced every 4 days. No $\mathrm{NaHCO}_{3}$ was added to the control solution.

\section{Measurement of morphological features}

The number of leaves on each plant was counted three weeks after Fe deficiency was imposed. Whole shoot and root lengths were measured for each plant sample using a ruler. For measurement of fresh weight of root, roots were harvested and then wiped with clean tissue paper before measuring weight in electronic balance. Fresh weight of shoot was directly measured after harvesting. For measuring dry weight, roots and shoots were quickly rinsed in deionised water and then wiped with clean tissue paper. Root and shoot samples were then dried in an oven at $70^{\circ} \mathrm{C}$ for two days before dry weight was measured.

\section{Measurement of chlorophyll concentration}

A chlorophyll content of leaves was determined spectrophotometrically as described previously by Lichtentaler and Wellburn with modifications (1985). Firstly, $100 \mathrm{mg}$ leaf was weighted and placed in $95 \%$ acetone in a $5 \mathrm{ml}$ falcon tube. The leaf sample was then grinded using mortar-pestle. The homogenate was filtered through whatman filter and was centrifuged at $2500 \mathrm{rpm}$ for $10 \mathrm{~min}$. The supernatant was separated and the absorbance were read at 662 (chlorophyll $a$ ) and 646 (chlorophyll $b$ ) on spectrophotometer. The amount of these pigments was calculated according to the formula given by Lichtentaler and Wellburn (1985).

\section{Determination of Fe content in leaves}

Firstly, the leaf samples $(1 \mathrm{~g})$ were digested as followed by Huang et al. (2004). Briefly, the dried leaf sample were predigested (overnight) sample and $\mathrm{HNO}_{3}$ mix is heated at $75{ }^{\circ} \mathrm{C}$ for $10 \mathrm{~min}$, followed by $109{ }^{\circ} \mathrm{C}$ for $15 \mathrm{~min}$. After cooling for $10 \mathrm{~min}, 1 \mathrm{ml}$ of $\mathrm{H}_{2} \mathrm{O}_{2}$ was added to each vessel through the ventilation hole and the sample mix is heated at $109{ }^{\circ} \mathrm{C}$ for a further $15 \mathrm{~min}$. The samples were then analysed for Fe concentration by Flame Atomic Absorption Spectroscopy (AAS) outfitted with ASC-6100 auto sampler and air-acetylene atomization gas mixture system (Model No. AA-6800, Shimadzu). Standard solutions of Fe were prepared from their respective concentration of $1000 \mathrm{ppm}$ stock solutions (Shimadzu), from which further serial dilutions $(0.1-4 \mathrm{ppm})$ were made to cover the optimum absorbance range for the standard calibration curve. For the determination, two solutions were prepared for each sample. Reagent blank determinations were used to correct the instrument readings.

\section{Statistical analysis}

Statistical analyses ( $\mathrm{t}$-test) were performed using Genstat software ( $14^{\text {th }}$ Edition). Significance was set at $\mathrm{p} \leq 0.05$. Three replications of each sample have been used for all experiments. 


\section{Results}

\section{Shoot parameters}

Number of leaves was counted in all genotypes grown on both Fe sufficient and Fe deficient hydroponic conditions. The number of leaves was not significantly reduced in 'BARI-1' and 'Local' variety due to Fe deficiency compared to Fe sufficient controls (Tab. 1). In contrast, leaf number was significantly reduced in 'Orca Onamica' and 'Prince' due to shortage of Fe compared to controls. Alike leaf number, shoot height was also influenced by Fe deficiency. Shoot height in 'BARI-1' and 'Local' variety was not significantly affected by Fe deficiency (Tab. 1). However, Fe deficiency caused significant decrease in shoot height in 'Orca Onamica' and 'Prince' compared to Fe sufficient plants. Fresh and dry weight of shoots was not significantly decreased in 'BARI-1' and 'Local' variety under Fe deficiency compared to Fe sufficient plants. However, Fe deficiency caused significant decrease in shoot's fresh and dry weight in 'Orca Onamica' and 'Prince' (Tab. 1).
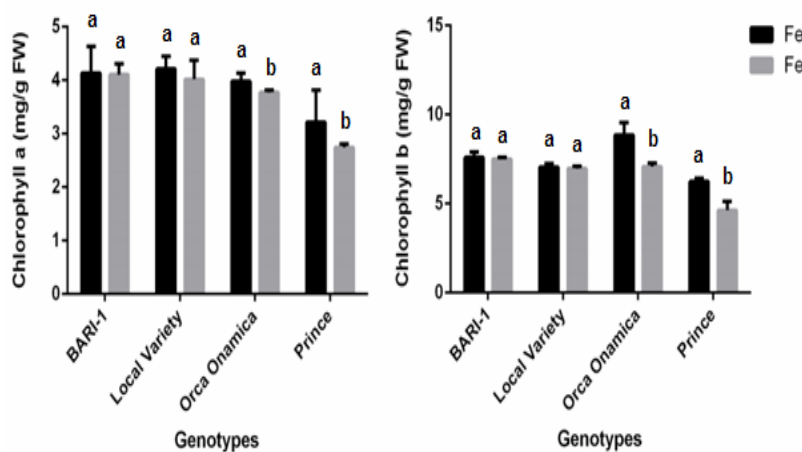

Fig. 1. Concentration of chlorophyll $\mathrm{a}$ and $\mathrm{b}$ in young leaves in a number of okra genotypes grown in Fe-sufficient $(\mathrm{Fe}+)$ and $\mathrm{Fe}$-deficient $(\mathrm{Fe}-)$ hydroponic culture. Data were taken 3 weeks after Fe deficiency was imposed. Different letters indicate significant differences between means \pm SD of treatments $(\mathrm{n}=3)$, comparisons were done for $\mathrm{Fe}+$ and $\mathrm{Fe}$ conditions

Tab. 1. Shoot parameters in different genotypes (cultivars) of okra grown on Fe sufficient (Fe+) and Fe deficient (Fe-) hydroponic culture; there were three replications for each sample; data were taken on three weeks old plants

\begin{tabular}{|c|c|c|c|c|c|c|c|c|c|c|c|c|}
\hline \multirow{2}{*}{ Cultivar } & \multicolumn{3}{|c|}{ No. of leaves (ppm) } & \multicolumn{3}{|c|}{ Shoot height $(\mathrm{cm})$} & \multicolumn{3}{|c|}{ Shoot fresh weight (g) } & \multicolumn{3}{|c|}{ Shoot dry weight $(\mathrm{g})$} \\
\hline & $\mathrm{Fe}+$ & $\mathrm{Fe}-$ & ' $t$ ' & $\mathrm{Fe}+$ & $\mathrm{Fe}-$ & ' $t$ ' & $\mathrm{Fe}+$ & $\mathrm{Fe}-$ & ' $t$ ' & $\mathrm{Fe}+$ & $\mathrm{Fe}-$ & ' $t$ ' \\
\hline BARI-1 & $7.5 \pm 0.5$ & $6.9 \pm 0.5$ & * & $12.7 \pm 1.0$ & $12.0 \pm 0.9$ & * & $0.6 \pm 0.3$ & $0.5 \pm 0.02$ & * & $0.09 \pm 0.03$ & $0.08 \pm 0.01$ & * \\
\hline $\begin{array}{c}\text { Local } \\
\text { Variety }\end{array}$ & $7.5 \pm 0.8$ & $6.4 \pm 0.5$ & $*$ & $15.4 \pm 1.1$ & $11.7 \pm 0.7$ & $*$ & $0.8 \pm 0.1$ & $0.6 \pm 0.08$ & * & $0.09 \pm 0.01$ & $0.07 \pm 0.2$ & * \\
\hline $\begin{array}{c}\text { Orca } \\
\text { Onamica }\end{array}$ & $9.9 \pm 1.0$ & $6.0 \pm 0.1$ & $* *$ & $15.4 \pm 1.2$ & $10.5 \pm 0.5$ & ** & $\begin{array}{c}1.0 \pm 0.1 \\
3\end{array}$ & $0.3 \pm 0.04$ & ** & $0.12 \pm 0.02$ & $0.06 \pm 0.01$ & ** \\
\hline Prince & $8.4 \pm 0.4$ & $6.0 \pm 0.2$ & $* *$ & $13.9 \pm 0.5$ & $10.5 \pm 0.9$ & ** & $1.0 \pm 0.1$ & $0.6 \pm 0.1$ & $* *$ & $0.13 \pm 0.03$ & $0.07 \pm 0.30$ & ** \\
\hline
\end{tabular}

't' test: ${ }^{*}$ Statistically non-significant; ${ }^{* *}$ Statistically significant

\section{Root parameters}

Length of roots was not significantly decreased in 'BARI-1' and 'Local variety' under Fe deficiency compared to the plants grown on Fe sufficient in vitro conditions. However, 'Orca Onamica' and 'Prince' were severely affected by Fe deficiency and their lengths of roots were significantly reduced under Fe deficiency (Tab. 2). Like length of roots, fresh and dry weights of roots were also showed similar sensitivity to Fe deficiency (Tab. 2).

Both fresh and dry weights of roots were not significantly decreased in 'BARI-1' and 'Local' variety due to $\mathrm{Fe}$ deficiency compared to controls. Whereas, $\mathrm{Fe}$ deficiency caused significant decrease in both fresh and dry weights of roots in 'Orca Onamica' and 'Prince'.

\section{Chlorophyll concentration}

The concentration of chlorophyll a was significantly reduced in 'Orca Onamica' and 'Prince' under Fe deficiency compared to Fe sufficient plants (Fig. 1). In contrast, no significant reduction in chlorophyll a concentration was observed in 'BARI-1' and 'Local variety' 1 due to Fe deficiency. Similar pattern was also observed for chlorophyll b under Fe deficiency compared to controls (Fig. 1).

\section{Fe content in leaves}

AAS was used to determine Fe concentration in young leaves of all four genotypes of okra grown in Fe-sufficient and $\mathrm{NaHCO}_{3}$-treated solution culture, with tissue taken 3

Tab. 2. Root parameters in different genotypes of okra grown on $\mathrm{Fe}$ sufficient $(\mathrm{Fe}+)$ and $\mathrm{Fe}$ deficient $(\mathrm{Fe}-)$ hydroponic culture. There were three replications for each sample. Data were taken on three weeks old plants

\begin{tabular}{|c|c|c|c|c|c|c|c|c|c|}
\hline \multirow{2}{*}{ Cultivar } & \multicolumn{3}{|c|}{ Root length $(\mathrm{cm})$} & \multicolumn{3}{|c|}{ Root fresh weight (g) } & \multicolumn{3}{|c|}{ Root dry weight (g) } \\
\hline & $\mathrm{Fe}+$ & $\mathrm{Fe}-$ & t-test & $\mathrm{Fe}+$ & $\mathrm{Fe}-$ & t-test & $\mathrm{Fe}+$ & $\mathrm{Fe}-$ & t-test \\
\hline BARI-1 & $5.7 \pm 0.24$ & $5.5 \pm 0.12$ & $*$ & $0.29 \pm 0.02$ & $0.27 \pm 0.02$ & $*$ & $0.26 \pm 0.01$ & $0.25 \pm 0.01$ & $*$ \\
\hline Local Variety & $5.7 \pm 0.71$ & $4.7 \pm 1.2$ & * & $0.25 \pm 0.02$ & $0.24 \pm 0.01$ & * & $0.22 \pm 0.02$ & $0.19 \pm 0.01$ & $*$ \\
\hline Orca Onamica & $7.1 \pm 1.10$ & $3.5 \pm 0.5$ & $* *$ & $0.29 \pm 0.01$ & $0.21 \pm 0.01$ & $* *$ & $0.28 \pm 0.01$ & $0.19 \pm 0.02$ & ** \\
\hline Prince & $6.3 \pm 0.31$ & $4.0 \pm 0.5$ & ** & $0.26 \pm 0.01$ & $0.19 \pm 0.02$ & ** & $0.23 \pm 0.01$ & $0.18 \pm 0.01$ & ** \\
\hline
\end{tabular}

't' test: ${ }^{*}$ Statistically non-significant; ${ }^{* *}$ Statistically significant 


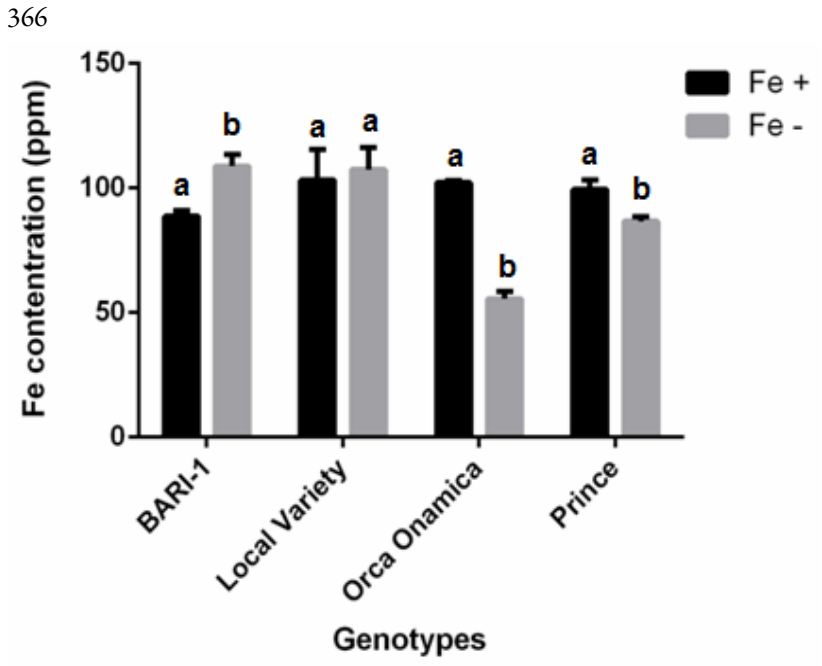

Fig. 2. Fe concentration in young leaves in a number of okra genotypes grown in $\mathrm{Fe}$-sufficient $(\mathrm{Fe}+)$ and $\mathrm{Fe}$-deficient $(\mathrm{Fe}-)$ hydroponic culture. Data were taken 3 weeks after $\mathrm{Fe}$ deficiency was imposed. Different letters indicate significant differences between means \pm SD of treatments $(n=3)$, comparisons were done for $\mathrm{Fe}+$ and $\mathrm{Fe}$ - conditions

weeks after $\mathrm{NaHCO}_{3}$ treatment. Under $\mathrm{Fe}$ deficient conditions, the leaf $\mathrm{Fe}$ concentration significantly increased in 'BARI-1' compared to the plants grown in Fe-sufficient conditions (Fig. 2). In addition, Fe concentration was unchanged due to Fe deficiency compared to Fe sufficiency plants in 'Local variety'. In contrast, significant decline in Fe concentration was observed in leaves of 'Orca Onamica' and 'Prince' under Fe shortage compared to controls (Fig. 2).

\section{Discussion}

Screening of Fe-deficiency tolerant line has been mainly carried out in vivo by field tests. Moreover, screening of the okra genotypes for Fe deficiency was never studied. The present study reveals the potentiality of Fe deficiency tolerance in a number of Bangladeshi okra genotypes. Our results confirmed by different physiological parameters further pinpoint the efficiency of hydroponic culture for $\mathrm{Fe}$ efficient okra germplasm.

Fe deficient plants grown hydroponically showed the typical chlorosis within few days after the beginning of the experiments. Different growth parameters were severely affected by Fe-deficiency induced hydroponic conditions. Results suggest that Orca Onamica and Prince are unable to tolerate Fe deficiency or in other words, they are not efficient to operate mechanisms conferring Fe deficiency tolerance. In general, plants survive under Fe deficiency by operating a number of Fe-efficient mechanisms in roots. 'BARI-1' and 'Local variety' were not significantly affected by Fe deficiency in their length and fresh and dry weights of roots. It suggests that Fe-efficient mechanisms are actively present in root systems that eventually let them continue normal growth and development. In contrast, these root parameters are negatively affected in 'Orca Onamica' and 'Prince' resulting stunned root and poor root biomass.
Chlorophyll ( $a$ and $b$ ) and Fe concentrations in leaves of all genotypes were studied in both $\mathrm{Fe}$ sufficient and $\mathrm{Fe}$ deficient hydroponic conditions. Results suggest that 'BARI-1' and 'Local variety' are the Fe-deficiency tolerant line showing no significant reduction in chlorophyll $a$ and $b$; whereas, 'Orca Onamica' and 'Prince' were found to be Fesensitive. AAS data showing the Fe concentration in leaves were found to consistent with the chlorophyll concentration.

Based on these investigations, it is evident that genotypic variation exists in Bangladeshi okra analyzed cultivars for $\mathrm{Fe}$ deficiency tolerance. Taken as a whole, 'BARI-1' and 'Local variety' are highly tolerant to Fe deficiency, showing normal chlorophyll synthesis, Fe concentration and physiological growth. In contrast, 'Orca Onamica' and 'Prince' are highly sensitive and unable to survive or maintain normal growth and development under Fe deficiency.

This study also confirms the efficiency of hydroponic culture for screening okra genetic line for screening Fe or other mineral deficiency tolerance germplasm. This method overcomes the difficulty associated with the use of calcareous soils under field, greenhouse, and growth chamber conditions.

This paper provides the first evidences on the genotypic variations in okra plants in response to $\mathrm{Fe}$ deficiency. Results also enrich the knowledge for varietal characteristics of okra and can be used by farmers and plant breeders where Fe deficiency is a major obstacle for okra propagation. Efficiency of hydroponic culture for the successful screening of plant genetic lines may also be followed by future scientists.

\section{References}

Celik H, Katkat AV (2008). Effect of bicarbonate and irondeprivation on growth of different maize varieties. Am Eurasian J Agric Environ Sci 3(2):169-178.

Chaney RL (1984). Diagnostic practices to identify iron deficiency in higher plants. J Plant Nutr 7(1-5):47-67.

Dilruba S, Hasanuzzaman M, Karim R, Nahar K (2009). Yield response of okra to different sowing time and application of growth hormones. J Hortic Sci Orn Plants 1:10-14.

Dragonuk MB, Fehr WR, Jessen HJ (1989). Effectiveness of nutrient solution evaluation for recurrent selection for $\mathrm{Fe}$ deficiency of soybean. Crop Sci 29:952-955.

Dwyer LM, Tollenaar M, Houwing L (1991). A non destructive method to monitor leaf greeness in corn. Can J Plant Sci 71:505-509.

Hamze M, Ryan J, Mikdashi R, Sohl M (1987). Evaluation of chickpea (Cicer arietanum L.) genotypes for assistance of lime-induced chlrosis. J Plant Nutri 10:1031-1039.

Hoagland DR, Arnon DI (1950). The water-culture method for growing plants without soil. Cal Agri ExpStat Circ 347:1-32.

Kosegarten HU, Grolig F, Hoffmann B, Mengel K (1999). Apoplastic $\mathrm{pH}$ and $\mathrm{Fe} 3+$ reduction in intact sunflower leaves. Plant Phys 121:1069-4079.

Lichtenthaler HK, Wellburn AR (1985). Determination of 
total carotenoids and chlorophylls $\mathrm{a}$ and $\mathrm{b}$ of leaf in different solvents. Biol Soc Trans 11:591-592.

Lindsay WL (1984). Soil and plant relationship associated with iron deficiency with emphasis on nutrient interactions. J Plant Nutri 7:489-500.

Marschner H (1995). Mineral nutrition of higher plants. 2nd Ed., Acad. Press, Amsterdam.

Mengel K(1995). Iron availability in plant tissues - iron chlorosis on calcareous soils. In: Abadia J (Ed.), Iron Nutrition in Soils and Plants. Kluwer Academic Publishers, Dordrecht, The Netherlands, p. 389-397.

Molassiotis A, Therios I, Dimassi K, Diamantidis G, Chatzissavvidis C (2005). Induction of Fe(III)-chelate reductase activity by ethylene and salicylic acid in irondeficient peach rootstock explants. J Plant Nutr 28:669682.

Ndunguru J, Rajabu AC (2004). Effect of okra mosaic virus disease on the above-ground morphological yield components of okra in Tanzania. Sci Horti 99:225-235.

Reeves DW, Mask PL, Wood CW, Delano DP (1993). Determination of wheat nitrogen status with hand-helo chlorophyll meter: influence of management practices. J Plant Nutr 16:781-789.
Saifullah M, Rabbani MG (2009). Evaluation and characterization of okra (Abelmoschus esculentus L. Moench.) genotypes. SAARC J Agric 7:92-99.

Srinivasarao CH, Ganeshamurthy AN, Ali M, Venkateswar B (2006). Phosphorus and micronutrient nutrition of chickpea genotypes in a multi-nutrient-deficient typic Ustochrept. J Plant Nutr 29:747-763.

Tangolar SG, Onlu G, Tangolar S, Dasgan Y, Yilmaz N (2008). Use of in vitro method to evaluate some grapevine varieties for tolerance and susceptibility to sodium bicarbonate-induced chlorosis. In Vitro Cell Dev Bio Plant 44:233-237.

Yakop UM (2008). Genetic investigations of iron deficiency in field peas (Pisum sativum L.). PhD Thesis, School of Agriculture and Wine, The University of Adelaide, Waite Campus, PMB1, Glen Osmond, SA 5064, Australia.

Zribi K, Gharsalli M (2002). Effect of bicarbonate on growth and iron nutrition of pea. J Plant Nutr 25:2143-2149. 